\title{
Uma análise Formalista da narrativa gráfica $A$ Chegada: nem livro ilustrado nem comics, mas ambos
}

A Formalist analysis of the graphic narrative The Arrival: neither picturebook nor comics, but both

\author{
Eduardo A. B. M. Souza
}

narrativa gráfica, medium, comics, livros ilustrados, estranhamento, Formalismo russo

\begin{abstract}
Este artigo discute a linguagem das narrativas gráficas por meio da análise de $A$ Chegada, do autorilustrador australiano Shaun Tan. A partir da fundamentação teórica e analítica no movimento literário do Formalismo russo, argumentaremos que livros ilustrados e comics compartilham dos mesmos parâmetros para comunicação e constituem uma mesma forma de expressão. Então, analisaremos os dispositivos poéticos utilizados na obra para causar estranhamento, um efeito característico da percepção artística, ao transplantar a experiência do protagonista para o leitor. Por fim, concluímos que, na configuração da mensagem, o design necessariamente se posiciona em um espectro comunicacional entre o estranho e o automatismo.
\end{abstract}

graphic narrative, medium, comics, picturebooks, estrangement, Russian formalism

This paper discusses graphic narratives' language by analysing The Arrival, from the Australian author and illustrator Shaun Tan. Theoretically and analytically based on Russian Formalism literary movement, we will argue that picturebooks and comics share the same parameters to communicate and belong to the same means of expression. Thus we will analyse the poetic devices employed in this work to cause estrangement, the characteristic effect of the artistic perception, by transplanting the character's experience to the reader. At last we conclude that by shaping the message, design necessarily has to stand somewhere between the strange and the automatic.

\section{Introdução}

Nossa discussão parte de uma confusão aparentemente superficial. A Chegada é citada como uma obra que não se encaixa nem como livro nem como comics, mas é ambos: foi eleita livro ilustrado do ano de 2007 pelo Conselho Australiano de Livros Infantis, bem como o melhor álbum de 2008 no Festival d'Angoulême. Isso é significativo em duas escalas: 1) em específico, porque revela que a distinção entre livros ilustrados e comics consiste no modo como esses artefatos articulam os elementos visuais, e; 2) em geral, porque explicita como a configuração dos artefatos implica a construção de significados em sua recepção. Para análise, utilizaremos a abordagem do Formalismo Russo, que enfatizou a configuração da linguagem e os efeitos que pode exercer.

No início do século XX, Victor Shklovsky afirmou que a percepção tem uma tendência à algebraização - um processo de redução e automatismo - que caracteriza a experiência cotidiana. Quando a linguagem é utilizada assim, ela é considerada prosaica. Em oposição a isso, a arte é capaz de renovar a percepção e quebrar o automatismo por meio de dispositivos e procedimentos que fazem com que se torne poética. Essa quebra é o estranhamento (ostranenie). Por meio da exploração de sentidos subjacentes à definição de estranhamento de Shklovsky, evidenciaremos a estética como um modo de estruturar a percepção do mundo.

Analiticamente, os fundamentos Formalistas são: os atributos distintivos da Literatura - sua literaturidade -, a ênfase nos dispositivos literários e a insistência na forma e na técnica como parte do conteúdo. Tais aspectos são fundamentais para compreender 1) uma linguagem - no nosso caso, a visual - como um campo de possibilidades de configuração, e; 2) a obra como

Anais do 9 CIDI e 9 CONGIC

Luciane Maria Fadel, Carla Spinillo, Anderson Horta, Cristina Portugal (orgs.)

Sociedade Brasileira de Design da Informação - SBDI

Belo Horizonte | Brasil | 2019

ISBN 978-85-212-1728-2
Proceedings of the 9th CIDI and 9th CONGIC

Luciane Maria Fadel, Carla Spinillo, Anderson Horta, Cristina Portugal (orgs.)

Sociedade Brasileira de Design da Informação - SBDI Belo Horizonte | Brazil | 2019

ISBN 978-85-212-1728-2 
articulação dos dispositivos para causar determinado efeito. O estranhamento é o efeito geral da arte, resultado do modo poético de usar um medium - ou seja, uma 'linguagem'. Desse modo, a literaturidade se define pelo emprego de dispositivos artísticos, que causam estranhamento. Esse efeito se realiza quando o leitor sente a experiência por meio da forma artística, ou seja, trans-viva uma experiência de outrem por intermédio da obra.

A Chegada conta o processo de familiarização de um estrangeiro no país para o qual emigra. O livro ilustrado busca coincidir a experiência do personagem com a do leitor, usando dois procedimentos principais: por não usar palavras - sem tempo verbal, é como se a história estivesse sempre em movimento - e pela linguagem pictórica verossímil - que the confere um caráter de documentário. Assim, ao permitir que o leitor trans-viva a narrativa do estrangeiro, a experiência é percebida como real, apesar dos elementos fantásticos. Por conseguinte, a narrativa gráfica adquire efeito poético, pois desloca a percepção cotidiana para a artística, renovando-a.

Essa discussão evidencia o espectro que a atividade de configuração pode assumir na comunicação visual: entre o estranho e o automatismo. O design se preocupa, sobretudo, com a morfologia: configurar a mensagem de determinado modo; informar um conteúdo. Desse modo, a aproximação teórica e metodológica entre literatura e narrativas gráficas busca evidenciar como a configuração visual constitui uma linguagem - ou seja, um nível de significado inescapável em que o designer não pode ser considerado neutro (Cf. Souza et al. 2016). Constatar a opacidade dessa atividade é um passo crucial para a consolidação de uma teoria do design.

\section{A abordagem ético-estética do estranhamento}

Segundo a teoria literária do Formalismo russo, o conceito de forma possui importância fundamental; não se refere a características estilísticas da literatura, mas ao modo de perceber o mundo. Ela passa a ser 'não mais um envelope, mas uma coisa completa, algo concreto, dinâmico, autossuficiente e sem um correlativo de nenhuma natureza' (Eichenbaum, 2001[1926], p. 1069), que condiciona a própria percepção. Nesta seção, compreenderemos alguns pressupostos da teoria Formalista, em especial dos textos de Victor Shklovsky, a fim de evidenciar o significado da atividade de dar forma.

Apesar da alcunha pejorativa, os Formalistas se definiam como especificantes ou teóricos de abordagem morfológica. Essas denominações revelam, respectivamente, dois fundamentos do movimento: a insistência na especificidade e autonomia dos Estudos Literários e ênfase na obra literária e seus componentes. Em específico, Shklovsky não é de fácil sistematização; em muitos aspectos é um moderno pós-moderno: sua escrita é irônica, repleta de jogos de linguagem e fluida em conceitos e abordagens; seus textos são quase manifestos. Dois são particularmente significativos para compreender a sua perspectiva sobre a relação entre arte $e$ cognição. No primeiro, A ressurreição da palavra, de 1914, estabelece seus preceitos estéticos básicos: o objetivo da arte e o papel dos artistas. No segundo e mais famoso, $A$ arte como procedimento, de 1917, utiliza o estranhamento pela primeira vez em uma crítica aguda às correntes simbolistas, e delineia as preocupações do Formalismo.

Em A ressurreição da palavra (1914), Shklovsky apresenta o processo por meio do qual as palavras perdem suas imagens e morrem. Nos parágrafos concisos e fragmentários, a maior parte das ideias desenvolvidas posteriormente já estão postas: desde o conceito de forma até as questões de história da literatura. Em alguns aspectos, o texto é nostálgico: '[...] uma vez que você atinge a imagem que agora está perdida e oculta, mas embutida na origem da palavra, você é confrontado pela sua beleza - beleza que um dia existiu e agora se foi' (ibid.), mas o impulso moderno de ruptura fica evidente quando afirma que 'a velha arte já morreu, e a nova ainda não nasceu' (ibid., p. 46).

Ele estabelece o caráter cognitivo de sua teoria: no processo de redução de esforço cognitivo, deixamos de sentir e passamos a apenas reconhecer. No texto, exemplifica ocorrências da percepção artística - aquela em que a forma é sentida - com experiências religiosas, folclóricas e primitivas. Entretanto, a 'armadura de vidro' da familiaridade fossiliza as 
formas artísticas e a transforma da linguagem em cemitério das palavras. Ou seja, o destino das palavras é percorrer o caminho da poesia para a prosa; assim, normalizam seu significado e perdem sua imagem. De maneira análoga, isso ocorre também com a percepção do mundo. Por isso, ele postula o objetivo da arte como 'restaurar a sensação do homem com o mundo, ressuscitar coisas e matar o pessimismo' (Shklovsky, 1973[1914]).

Quando publica A arte como procedimento (1917), Shklovsky radicaliza seu discurso, aprimorando as ideias delineadas anteriormente. Para os Formalistas, a psicologia era sinônimo de economia da percepção. Isso está relacionado a uma discussão da época sobre a imagem na literatura: os simbolistas defendiam que a arte se caracterizava pelo simples uso de imagens e que, por isso, requeria menos esforço da percepção. $A$ arte era uma crítica belicosa e irônica, sobretudo, contra essa ideia: para ele, a poesia não pode ser definida como pensar por imagens, pois o pensamento imagético por si só não é poético.

Assim, a dimensão perceptiva se torna dependente das qualidades da obra, pois Shklovsky demonstrou que 'a percepção da forma resulta de técnicas artísticas específicas que forçam o leitor a experienciar a forma' (Eichenbaum, 2001[1926], p. 1070). A presença da imagem literária, então, perde importância: ela pode ser tanto prosaica quanto poética, a depender do objetivo para o qual é utilizada. Logo, o artista se ocupa em organizar as imagens em vez de criá-las. A obra é concebida, então, como um artefato feito por meio de procedimentos para torná-la o mais obviamente artística quanto possível (Shklovsky, 1965[1917]).

Nesse sentido, surge a noção de estranhamento. Há diversas divergências de tradução, conceituação e mesmo disputas teóricas circundando esse conceito até sua recepção hoje (Cf. Souza, 2016). De qualquer modo, Shklovsky o propôs como um propósito geral da arte, usando os mais diversos exemplos espalhados pela história da Literatura: desde adivinhas eróticas de Boccacio, passando pelo realismo de Tolstói até chegar na poética transmental de Mayakovsky. Assim, define seu conceito neste trecho:

Então, a fim de restaurar a sensação da vida, de sentir as coisas, de tornar a rocha rochosa, existe o que chamamos de arte. O propósito da arte é dar-nos a sensação de algo como vemos e não como reconhecemos; o procedimento da arte é o procedimento para o 'estranhamento' das coisas, um procedimento da forma elaborada que aumenta o esforço e a duração da percepção, porque na arte o processo perceptivo é direcionado a si próprio e deve ser prolongado. Arte é um modo de experienciar o fazer de algo, mas a coisa feita na arte não é importante. (Shklovsky, 1917 apud Robinson, 2008 tradução e negrito nossos, itálico no original)

Vale ressaltar que Shklovsky aponta que a característica própria da arte é o efeito do estranhamento, mas que 'a coisa feita na arte não é importante'. Assim, reconhece que o próprio objeto artístico - a poesia, a pintura, o romance, etc. - vai, também, se fossilizar e perder sua artisticidade.

Todavia, é necessário ainda explicitar certos sentidos para compreender a relação entre forma, percepção e, em última instância, seu caráter ético: o trabalho e o fazer de algo. Os termos em russo que explicam o estranhamento pertencem à mesma raiz etimológica de trabalho (Robinson, 2008). Nesse sentido, o processo de automatização da percepção é análogo à imagem da fábrica - através da repetição, o trabalho se torna tão automático que sequer é lembrado. Porém, a ênfase de Shklovsky seria no trabalho de um artesão que, de fato, experimenta o fazer de algo, conferindo ares marxistas à leitura do estranhamento como um antídoto para a alienação. Isso se refere ao princípio da sensação da forma, que é caracterizado pelo aumento do esforço e da duração da percepção.

O fazer de algo se relaciona ao trabalho, mas não se encaixa facilmente na lógica do texto, fazendo com que tradutores desviassem o conceito para outras direções no inglês ( $C f$. Robinson, 2008, p.116) e também no francês/português, como 'devir' (Shklovsky, 1976). Segundo Robinson (2008), o termo em russo utilizado por Shklovsy para o experienciar significaria literalmente 'trans-viver', que indica a capacidade da arte de ter a experiência através do outro - a palavra em russo às vezes é usada para empatia (ibid.). Isso quer dizer que uma obra de arte é capaz de mediar a experiência alheia e o leitor, uma vez que ele se 'projete empaticamente no ato de fazer o trabalho através do qual a obra foi feita' (ibid., p. 117). Por isso, a obra, não importa, a não ser como canal entre a sensação de empatia e o leitor; o autor e o leitor participam do fazer de algo - 'não apenas a coisa poética, mas da coisa 
mundana como modelada imaginativamente [...] pela coisa poética' (ibid., p. 118).

Nessa seção, buscamos compreender a teoria Formalista da arte, sobretudo o conceito de estranhamento, para relacionar o conceito de forma com a percepção de maneira mais ampla e, sobretudo, com um posicionamento ético. Esse posicionamento se dá, necessariamente, pela compreensão do estranhamento para além de seu efeito cognitivo, aprofundando seus sentidos subjacentes: o trabalho e o fazer de algo. Desse modo, buscamos salientar o significado da atividade de dar forma na produção de artefatos comunicacionais. Na seção a seguir, delinearemos as ferramentas para análise de $A$ Chegada, também a partir da teoria Formalista.

\section{A abordagem de análise Formalista}

Depois de delinear alguns pressupostos do Formalismo russo e do estranhamento, trataremos das ferramentas para a realização da análise da obra. Para nós, é fundamental que a obra não seja reduzida para se conformar ao sistema; a análise deve se adequar à especificidade de cada obra. Por conseguinte, reuniremos a seguir conceitos instrumentais a fim de explicitar como se dará a nossa análise. A abordagem Formalista nos oferece uma série de pressupostos, que pode originar diferentes métodos, compreendidos como 'um conjunto de procedimentos utilizados no processo analítico de fato' (ibid., p. 3). Utilizaremos a síntese feita por Thompson (1988), para elencar as ferramentas analíticas; elas são maleáveis e devem manter a característica ostensiva com os livros ilustrados.

A unidade morfológica mais simples é o dispositivo (pryiom), 'um único elemento ou estrutura que desempenha um papel na obra' (Thompson, 1988, p. 15). Pressupondo que a obra é intencionalmente construída e resultou de uma série de escolhas - conscientes ou inconscientes - das pessoas que criaram, os dispositivos podem ser analisados em vista de sua função e motivação. Tynyanov (1971[1929]) definiu função como 'a inter-relação entre cada elemento com cada outro em uma obra literária e com o sistema literário como um todo' (p. 68); é o propósito a que serve qualquer dispositivo, que varia de obra para obra; um mesmo dispositivo pode exercer diferentes funções. Já a motivação é 'uma dica dada pela obra que nos inclina a decidir o que pode justificar a inclusão do dispositivo' (Thompson, 1988, p. 16).

As possibilidades do medium, ou seja, 'os elementos que fornecem material em potencial para variação' (Thompson, 1988), são chamados de parâmetros. A utilização característica dessas técnicas do medium constituirá o estilo em uma obra. Os dispositivos estilísticos podem servir à narrativa, por motivação composicional, criando estranhamento no nível narrativo. Por outro lado, podem ser usados para dificultar a narrativa e trazer atenção para si próprios.

A imagem poética emerge da articulação dos dispositivos artísticos presentes na obra. Nesse sentido, a teoria Formalista dispõe-se a explicitar como a obra realiza seu efeito artístico - que é sentido pelo crítico muito antes de iniciar a análise. Para determinar como o estranhamento se dá, utilizaremos o conceito de dominante, 'o princípio formal central que uma obra ou um grupo de obras usa para organizar seus dispositivos em um todo' (Thompson, 1988, p.43). É através dela que os níveis estilísticos, narrativos e temáticos vão se relacionar. As pistas para encontrá-la são dadas pelo destaque dos dispositivos mais importantes e intrigantes. Se encontrarmos uma estrutura em comum de funções que permeie os dispositivos, podemos considerar que essa estrutura compõe ou está intimamente relacionada à dominante.

Essa abordagem será adequada às características do medium das narrativas gráficas através de suas propriedades, que servirão como princípio de organização: a artrologia, a multimodalidade e a ordem pictórica (Cf. Souza; Miranda; Porto Filho, 2016). Uma vez que são características pelas quais próprio medium opera, é nessas propriedades que identificaremos os dispositivos da obra e suas relações a fim de compreender como ela visa ao estranhamento. Eles serão, portanto, os parâmetros de nossas análises. 


\section{Análise de caso: $A$ Chegada}

A figura do estrangeiro é chave para $A$ Chegada. Argumentando que a relação do estrangeiro com a língua materna é 'diretamente responsável pela articulação da distância estética', Kempinska (2013) identifica três figuras distintas do estrangeiro-fruidor de uma obra: o desenraizado, o outsider e o exilado. Assim, argumentaremos que A Chegada é uma obra realista, cuja dominante é a experiência do imigrante e cujos procedimentos principais são metaforizar fatos e materializar fantasias por meio dos elementos fantásticos. Assim, a narrativa é capaz de 1) retirar essa narrativa do espaço-tempo conhecido e 2) fazer com que o leitor sinta o mesmo que o protagonista. Assim, ao transplantar a sensação do personagem outsider para o leitor, a experiência é percebida como real, embora seja fantástica.

O desenraizado é uma figura idealizada, que ao liberar-se do solo, 'permite [...] uma visão ampla, ao mesmo tempo mais disponível e mais distanciada da realidade em geral' (Kempinska, 2013). Ele se identifica como livre, autônomo e distanciado, capaz de sobrevoar as culturas e línguas, de pertencer a um espaço extralinguístico. Desse modo, essa migração estética 'envolve principalmente as faculdades imaginativas e cognitivas do sujeito, cujo corpo permanece indiferente durante o percurso todo' (ibid.).

O outsider é composto por um gesto fundamentalmente mais violento, 'pois corresponde a uma tentativa, nunca completada, de 'se arrancar' do domínio da língua própria' (ibid.). Essa figura tem como objetivo romper com uma unidade ou repetição, e é exemplificada por Kempinska pelo efeito do ostranenie. A irrupção do automatismo da percepção através da linguagem proposta pelos Formalistas nos direciona a uma constante pluralidade da experiência, uma 'renovação que invalida, por um momento, a relação do fruidor com a passagem do tempo e com a memória' (ibid.).

Por fim, o exilado parece apontar para uma transferência realizada pela psique: aquilo que causa inquietação clínica é transferido para a figura do estrangeiro - identificando-o, assim, com a figura do. A relação com a língua é fundamentalmente ambivalente pois é, ao mesmo tempo, materna e estrangeira, descarrilhando para 'a violência das relações, não raramente transformadas em catástrofes, os colapsos da subjetividade e a substituição do discurso pelo corpo' (ibid.). Na estética, se reflete na incapacidade de controlar a distância, pois esse exilado 'transforma tudo em questão pessoal, oscilando, de forma incoerente e descontrolada, entre 0 afastamento e a intimidade' (ibid.). A Figura 1 apresenta um esquema demonstrando os principais elementos da narrativa, inclusive sua estrutura e metáforas recorrentes.

Figura 1: Esquema geral da análise de $A$ Chegada.

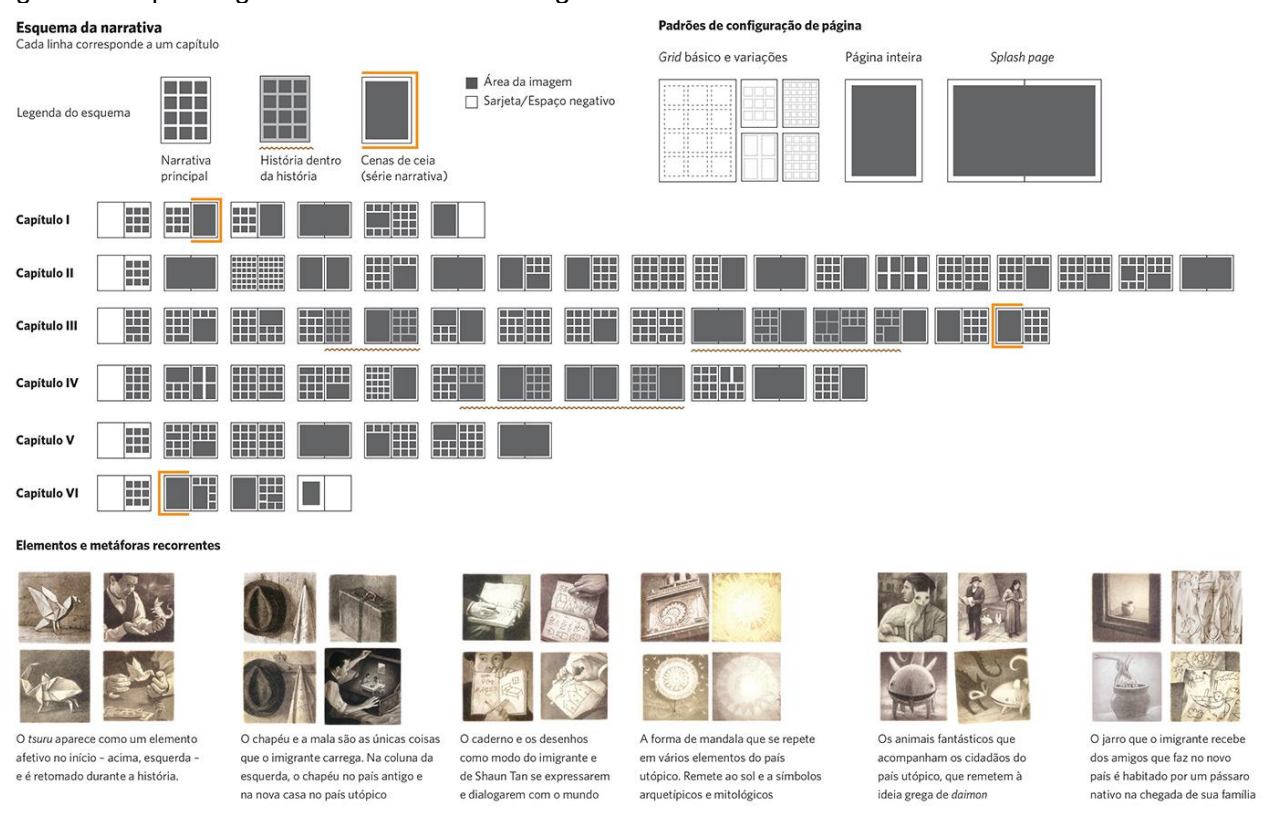


Apesar dos diversos elementos fantásticos que povoam a narrativa, $A$ Chegada é uma obra realista. Segundo Thompson (1988), uma obra é definida como realista segundo o tipo predominante de motivação presente na obra; 'se os indícios nos pedem para apelar ao nosso conhecimento do mundo real [...] nós podemos dizer que a obra está usando a motivação realista' (p. 198). Não devemos tomar o sentido mais vulgar de 'realista', sobretudo quando tratamos de representações; a verossimilhança do desenho, de fato, é um dos dispositivos que nos induz a uma interpretação mais literal, mas a motivação realista se dá, sobretudo no material que deu origem à obra.

A figura do imigrante presente em A Chegada é o outsider. Embora os personagens se arranquem da terra natal contra sua vontade, a narrativa consiste no esforço de familiarizar-se. A ênfase na possibilidade de adaptação do imigrante com esse universo estranho revelam esse movimento duplo de estranhamento e familiarização como parte de um mesmo contínuo. $\mathrm{Na}$ narrativa arquetípica de Shaun Tan, o processo de adaptação é bem-sucedido e o estrangeiro é capaz de se habituar com a nova vida com sua família - mas Kempinska (2013) aponta possíveis desfechos mais violentos com a figura do exilado.

A extensa pesquisa no processo de criação do livro faz com que a temática do material seja muito significativa na obra final. Esse material foi coletado em relatos pelo próprio Shaun Tan de imigrantes de diversas culturas - inclusive seu pai - quanto de uma pesquisa feita no museu de uma das principais estações de imigração dos Estados Unidos, Ellis Island (Figura 2). Portanto, a experiência arquetípica do imigrante - fundamentada na pesquisa histórica - está trançada na obra, de maneira que se torna sua dominante.

Figura 2: Comparação da fotografia da estação de imigração em Ellis Island, EUA, (dir.) e página de $A$ Chegada (esq.).
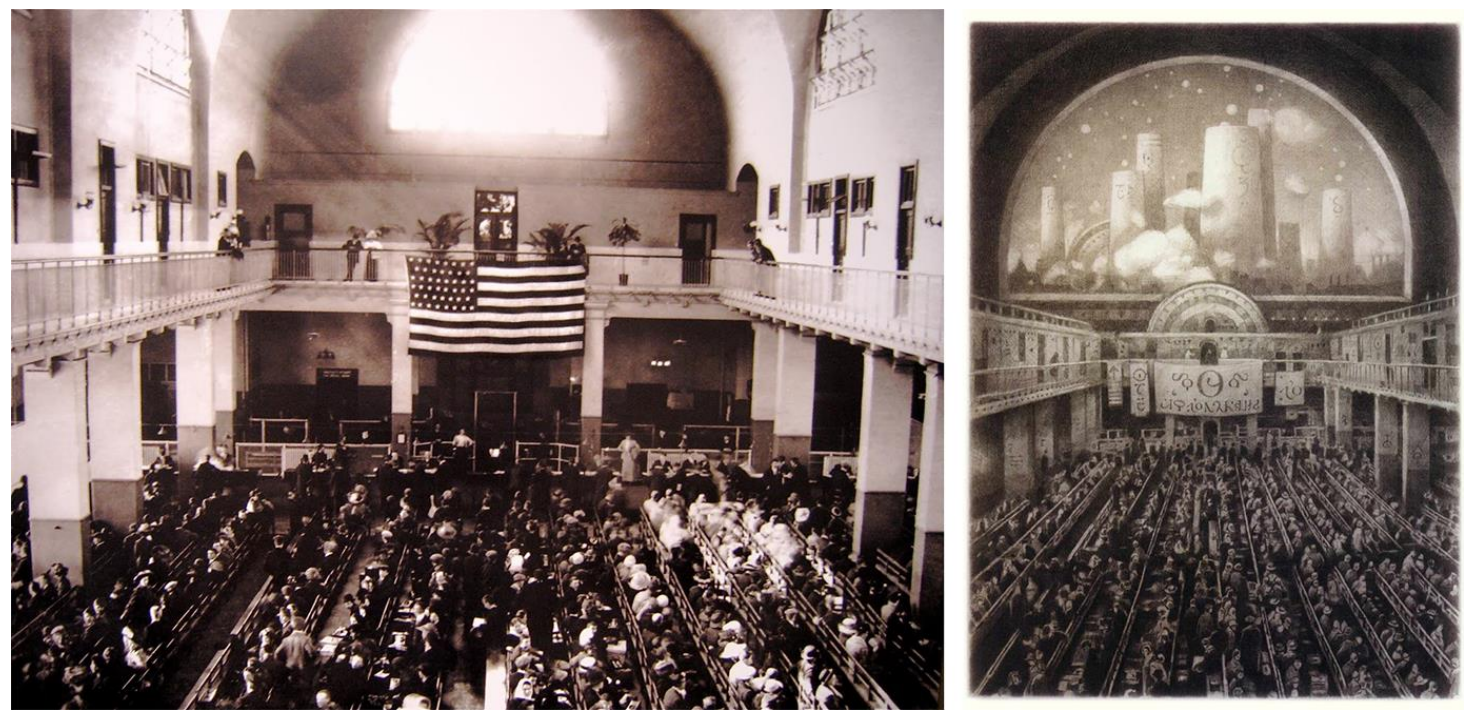

Em A Chegada, o procedimento geral de Shaun Tan da ilustração indireta - 'tentar encontrar um equivalente metafórico para um tema ou experiência, uma representação imaginária em vez de uma literal' (Tan, 2010) - funciona em contraste com a motivação realista. Esse aspecto fantástico da narrativa opera tanto na descontextualização de espaço e tempo quanto em explicitar a experiência através da materialização da sensação. Assim, o protagonista imigrante também é distanciado da realidade, efetuando um contraste entre sua singularidade e sua universalidade.

A presença dos elementos fantásticos enquanto metáforas das experiências criam aberturas de interpretação para que permita ao leitor dar-Ihes significado. Esse aspecto quase mitológico transforma a narrativa em algo arquetípico, e por isso, atemporal e extraterritorial - em última instância, estranho. Esse distanciamento opera também pela linguagem pictórica: embora verossímil, a representação explicita-se como desenho através de hachuras e texturas visíveis. Portanto, a ordem pictórica se reafirma como apenas um modo de ver o mundo, em vez de 
pretender-se a própria realidade.

A partir das referências visuais e pesquisa históricas, Shaun Tan confere realidade à narrativa. Todavia, a maneira como ela é representada não é vulgarmente documental ou mimética: o material adquire outras características quando é incorporado na obra. $\mathrm{O}$ procedimento faz com que os fatos históricos sejam transformados poeticamente em sensação: a verossimilhança documental da narrativa e das imagens que a compõem transmutam-se por meio da atitude poética.

A presença desses movimentos de afastamento e aproximação simultâneos tornam $A$ Chegada exemplar do pós-modernismo moderno de Shaun Tan, de modo que 'a fusão de ideias e dispositivos modernistas e pós-modernos permite-lhe criar seu próprio universo sutil, intrigante e esperançoso' (Devos, 2011). Enquanto a narrativa possui características marcadamente pós-modernas como 'indeterminação, fragmentação, hibridização (como paródia ou pastiche), quebra de cânones e um senso extremo de ironia' (ibid.), sua narrativa não implica na ausência de significado ou em qualquer tipo de niilismo. Pelo contrário, a partir de narrativas que tratam, das mais diversas formas, da questão de pertencimento, ele é capaz de costurar uma espécie de 'grande narrativa'.

A dominante realista da obra se reflete nas questões de artrologia. A Chegada é uma narrativa de sequências temporais quase sempre regulares, de modo que sua estrutura geral é bastante estável com apenas três padrões de configuração de página: a splash page, a página inteira e a modular, com um grid predominante de 12 quadrados por página - que varia em raras exceções (Figura 3). Isso confere uma mudança de tempo constante ao longo da narrativa, permitindo que a ênfase se desse nos gestos e ações dos personagens, a fim de criar uma espécie de narração expressiva, 'lidas' como frases e parágrafos visuais (Tan, 2010).

Figura 3: Montagem com as quatro primeiras pranchas do segundo capítulo demonstram como o ritmo se desenvolve na narrativa. O zoom out de dentro da cabine para a splash page do barco diante da tempestade e a longa passagem de tempo através dos pequenos quadros com os estudos de nuvens.
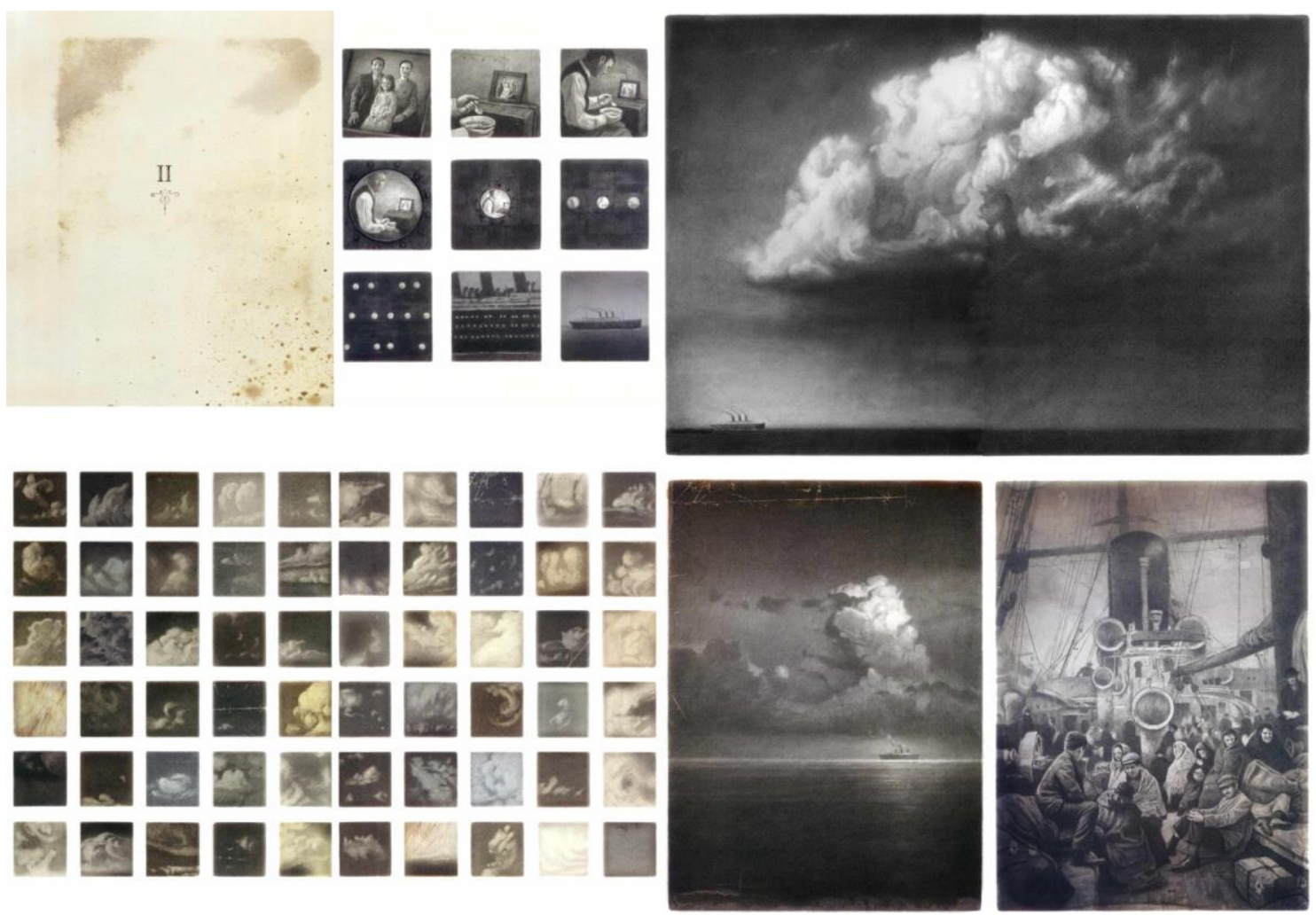

A respeito da multimodalidade, essa obra é geralmente descrita como uma narrativa sem palavras, silenciosa ou muda. No entanto, esses adjetivos não explicam a maneira como o 
verbal se desenvolve na história. A Chegada não é uma narrativa sem palavras, é uma narrativa com palavras ininteligíveis. Um dos procedimentos mais cruciais para indicar o deslocamento do imigrante é a presença de palavras e signos verbais que não compõem sentido algum para o leitor. Esse efeito desorientante é atingido pelo 'rearranjo cirúrgico de letras e números romanos, usando tesoura e fita adesiva' (Tan, 2010), que resulta em um alfabeto composto por fragmentos familiares, mas que, em conjunto, se tornam crípticos (Figura 4).

Figura 4: O alfabeto inexistente reforça a familiaridade estranha do novo país. Apesar de formado por partes de caracteres latinos, eles se tornam signos que não significam nada. Reprodução de Tan (2010)

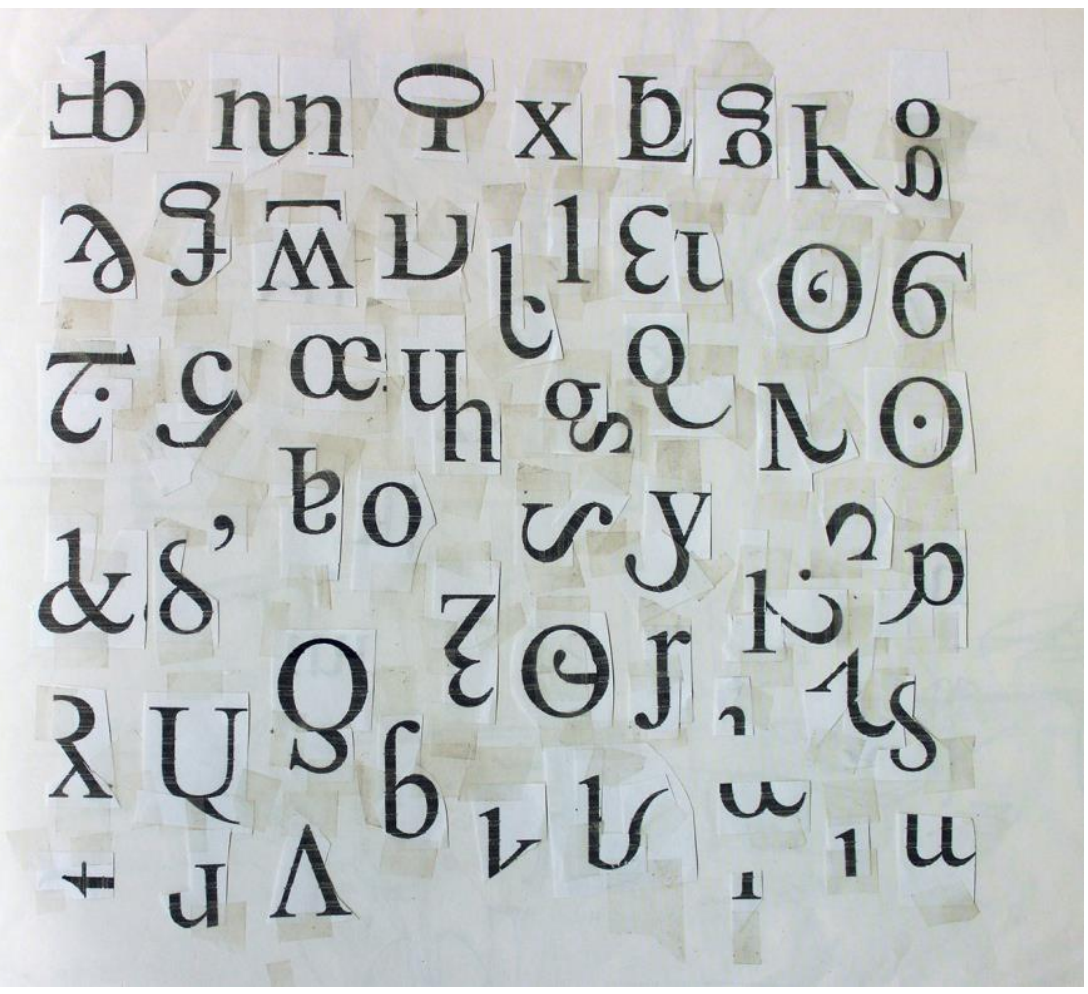

Isso tem um papel fundamental em nos fazer acompanhar a sensação do choque cultural do protagonista e em seu subsequente processo de familiarização, lembrando-nos 'da nossa dependência da palavra escrita para a segurança e autoridade quando se trata de significado' (ibid.). A presença do texto ininteligível já causa impacto na falsa folha de rosto, em que a única coisa que podemos ler de maneira intuitiva é o nome de Shaun Tan grafado com caracteres imaginários parecidos com os romanos. Além das informações de publicação - título, editora, dedicatória - todo o texto ininteligível é intraicônico, ou seja, está inserido nas ilustrações.

Uma vez que não há texto verbal para criar relações de significado com a imagem, a ordem pictórica assume uma importância muito maior tanto na narração de ações quanto na criação de significado. Assim, argumentamos que eles se estruturam em três principais dispositivos: a linguagem gráfica, a verossimilhança do protagonista e a intertextualidade pictórica.

Shaun Tan adapta sua linguagem gráfica segundo a história que precisa contar - o 'estilo' da ilustração também se torna um dispositivo de ordem pictórica. $O$ aspecto documental decorrente de sua pesquisa fez com que ele se sentisse compelido a trabalhar de modo difícil e meticuloso (Tan, 2010). Assim, também se estabelece uma relação com o cinema realista italiano. Por outro lado, a ordem pictórica não é livre de ambiguidades. Apesar de ser um desenho 'realista', Shaun Tan não quis se submeter a um trabalho excessivamente fotográfico, uma vez que 'desenho não se trata de reproduzir: em vez disso, ele nos apresenta a uma realidade abstraída, um outro mundo que flutua atraentemente acima do nosso' (ibid. p.42).

Há uma camada metalinguística quando observamos que o protagonista parece com o 
próprio Shaun Tan: há relação entre os problemas experimentados pelo imigrante com os seus próprios enquanto artista visual. Com isso, ele desnuda o próprio dispositivo do desenho, explicitando sua motivação artística em meio à predominância realista. Em última instância, o caderno do imigrante e toda obra de Tan são igualmente maneiras de entender e organizar o mundo e estabelecer contato com outras pessoas - remetendo diretamente ao fazer de algo e ao trans-viver do ostranenie.

Por fim, o dispositivo da intertextualidade pictórica decorrente da dominante realista se estabelece ao longo do livro para conferir mais realidade à narrativa. Nos desenhos, há diversas referências pictóricas a imagens documentais de imigrantes e viagens.

\section{Conclusão}

Para compreender essa obra complexa, definimos que a característica dominante é a experiência do imigrante, fundamentado por muita pesquisa documental e coleta de relatos por Shaun Tan. Essa dominante faz com que as motivações indicadas na obra sejam fundamentalmente realistas, ou seja, apelam para nosso conhecimento do mundo real, embora interpretemos livremente as criaturas e elementos fantasiosos presentes no mundo narrativo. A partir do procedimento de metaforizar fatos e materializar elementos fantásticos, Shaun Tan é capaz de deformar as expectativas realistas para transplantar a sensação do imigrante para o leitor e expor o olhar do estrangeiro, a fim de desfamiliarizar não o mundo narrativo - pois ele já funciona segundo uma lógica estranha -, mas o próprio mundo real.

Assim, A Chegada é exemplar para estabelecer os livros ilustrados como uma forma de expressão própria. Por articular os dispositivos desse medium sem obedecer estritamente às convenções, esse artefato é, ao mesmo tempo, comics e livro ilustrado. Ademais, por meio da análise, buscamos demonstrar que a abordagem Formalista é adequada para compreender que é a articulação dos dispositivos em uma obra é que definem essas convenções, embora disponham dos mesmos parâmetros que tantas outras obras. De particular interesse para os próximos desdobramentos teóricos é investigar a noção de imagem quando está atrelada à Literatura e à linguagem verbal. Uma investigação mais detida - inclusive, de cunho histórico (Cf. Souza, 2019) - pode ajudar a eliminar dicotomias entre a linguagem verbal e visual a fim de permitir modos de comunicação com mais camadas de significado.

Enfim, segundo a concepção de Shklovsky, podemos conceber os artefatos comunicacionais como arranjo, configuração e articulação, enfraquecendo a ideia abstrata de 'criação'. Isso permite fazermos outras aproximações com a atividade do designer. Desse modo, podemos esquecer oposições datadas como aquelas feitas entre arte e design, pois ambos tratam de criar modelos estéticos a partir da configuração de artefatos. Compreender um contínuo comunicacional dos artefatos pode levar a uma teoria mais consolidada do design.

\section{Referências}

Eichenbaum, B. (2001[1926]) The theory of the 'formal method'. In: Leitch, V. B. (ed.). The Norton Anthology of Theory and Criticism. Nova York: W. W. Norton \& Company.

Devos, L. (2011) Not all that's modern is post: Shaun Tan's grand narrative. Bookbird: A Journal of International Children's Literature. Baltimore: John Hopkins University Press, 49(4).

Kempinska. O. G. (2013) O olhar estrangeiro e a estética. Aletria: Revista de Estudos de Literatura. Belo Horizonte: Programa de Pós-Graduação em Estudos Literários da Faculdade de Letras/UFMG, 23(1).

Robinson, D. Estrangement and the Somatics of Literature. Baltimore: The Johns Hopkins University Press, 2008.

Shklovsky, V. (1965). Art as Technique. In: Russian Formalist Criticism: Four Essays. Traduzido por Lee T. Lemon e Marion J. Reis. Lincoln: University of Nebraska Press. 
. (1973[1914]) The resurrection of the word. In: Bann, S.; Bowlt, J.E. (eds.) Russian Formalism: A collection of articles and texts in translation. New York: Barnes and Noble.

Souza et al. (2016). Alternativas epistemológicas para o design da informação: a forma enquanto conteúdo. Revista Brasileira de Design da Informação. São Paulo, 13(2).

Souza E. A., MIRANDA E. R. \& PORTO FILHO G. (2016). A narrativa gráfica enquanto medium. Revista Brasileira de Design da Informação. São Paulo, 13(3).

Souza, E. (2016). O estranhamento nos livros ilustrados de Shaun Tan. Dissertação (Mestrado). Recife, Pernambuco. Universidade Federal de Pernambuco, 2016.

. (2019). Por que imagem não é literatura?. Jornal Rascunho, 226, Fevereiro de 2019. Disponível em: <http://rascunho.com.br/por-que-imagem-nao-e-literatura/> Último acesso em 16 de julho de 2019.

Tan, S. (2010) Sketches from a Nameless Land: The Art of The Arrival. Sydney: Hachette Australia.

Thompson, K. (1988) Breaking the glass armor: Neoformalist film analysis. New Jersey: Princeton University Press.

Tynyanov, Y. (1971[1929]). On Literary Evolution. In: Matejka, L.; Pomorska, K. (eds.). Readings in Russian Poetics: Formalist and Structuralist Views. Cambridge: The MIT Press.

\section{Sobre o autor}

Eduardo Souza, Doutorando, IFPE, Brasil <hello@souzaeduardo.com> 